\title{
Encefalopatias Epilépticas Infantis: O Novo Paradigma do Diagnóstico Genético
}

\author{
Epileptic Encephalopathies of Childhood: The New \\ Paradigm of Genetic Diagnosis
}

Rita MARTINS $\triangle^{1}$, Oana MOLDOVAN ${ }^{2}$, Ana Berta SOUSA ${ }^{2}$, António LEVY ${ }^{3}$, Sofia QUINTAS
Acta Med Port 2020 Jun;33(6):415-424 - $\underline{\text { https://doi.org/10.20344/amp.12550 }}$

\begin{abstract}
RESUMO
Introdução: As encefalopatias epilépticas da infância constituem um grupo de patologias de início precoce e prognóstico neurológico reservado. O desenvolvimento das novas técnicas de estudo genético foi responsável pela identificação de novos genes implicados. Nos últimos anos, assistimos a uma revolução no seu paradigma diagnóstico. Contudo, actualmente não existem recomendações internacionais consensuais sobre a abordagem à investigação das encefalopatias epilépticas genéticas. Pretendemos discutir o conhecimento actual sobre a arquitectura genética das encefalopatias epilépticas infantis.

Material e Métodos: Realizou-se uma revisão da literatura das encefalopatias epilépticas infantis genéticas e estudos utilizados no seu diagnóstico. Propomos uma abordagem sistematizada através de um algoritmo diagnóstico a utilizar na prática clínica.

Resultados: Inicialmente deve-se determinar o fenótipo do doente com base no tipo de crises, padrão electroencefalográfico e neuroimagem. Nos doentes sem etiologia após resultados de ressonância magnética cranioencefálica, deve-se realizar estudo metabólico apropriado para o diagnóstico prioritário de doenças metabólicas tratáveis. A investigação de outras causas genéticas deve ser considerada, sobretudo perante características fenotípicas sugestivas. Primeiro deve-se realizar a análise de microarray cromossómico, principalmente se existirem alterações dismórficas ou polimalformativas. Se esta for negativa e/ou não existirem elementos físicos distintivos, o próximo passo deve ser realizar os painéis multigénicos ou sequenciação de exoma. Os estudos dirigidos do gene devem ser reservados para quando o fenótipo é indicativo de uma síndrome específica.

Conclusão: A marcha diagnóstica das encefalopatias epilépticas tornou-se complexa com a expansão de conhecimentos genéticos. Este novo paradigma apresenta implicações terapêuticas, prognósticas e de aconselhamento familiar.

Palavras-chave: Criança; Encefalopatias; Epilepsia/diagnóstico; Testes Genéticos
\end{abstract}

\section{ABSTRACT}

Introduction: Epileptic encephalopathies of childhood are characterized by early seizure-onset and adverse neurological outcomes. The development of new genetic techniques has allowed an exponential identification of the genes that are involved. Over the last years, we have observed a revolution in the diagnostic paradigm. However, there are no international guidelines regarding the diagnosis of genetic epileptic encephalopathies. We aim to discuss the current knowledge about the genetic architecture of epileptic encephalopathies of childhood.

Material and Methods: review of the literature about infantile epileptic encephalopathies and the genetic tests currently available. A systematic approach and a diagnostic algorithm to use in clinical practice were proposed.

Results: Initially the patient's phenotype should be determined based on the seizure type, electroencephalogram pattern and neuroimaging. Patients with unclear etiology after brain magnetic resonance imaging should undergo an appropriate metabolic investigation to promptly exclude treatable conditions. Further studies should also include other genetic causes, mainly if associated with particular phenotypic features. Chromosomal microarray analysis should be firstly considered, particularly if dysmorphic or polymalformative abnormalities are present. If this is negative and/or there are no physical features, the next step should be next-generation sequencing multigene panels or whole-exome sequencing. Single gene study should only be considered when the patient's phenotype is highly suggestive of a specific syndrome.

Conclusion: The revolution of the genetic knowledge about epileptic encephalopathies of childhood has led to a complex diagnostic approach. This new paradigm poses significant implications in genetic counselling, treatment and prognosis.

Keywords: Brain Diseases/complications; Child; Epilepsy/diagnosis; Genetic Testing

\section{INTRODUÇÃO}

O desenvolvimento das novas técnicas de estudo do genoma humano conduziu ao exponencial conhecimento sobre a arquitectura genética das encefalopatias epilépticas infantis (EEI). ${ }^{1}$ Consequentemente, a sua marcha diagnóstica tornou-se particularmente complexa na prática clínica.

As EEI representam um grupo de epilepsias, na sua maioria de início precoce, de prognóstico neurológico desfavorável. As apresentações sindromáticas são variáveis e dependentes da idade, incluindo a síndrome de Ohtahara, encefalopatia mioclónica precoce, espasmos infantis e/ou síndrome de West, epilepsia migratória maligna do lactente, síndrome de Dravet e síndrome de Lennox-Gastaut. ${ }^{2,3} \mathrm{~A}$ ocorrência de actividade epiléptica durante o período crítico de maturação cerebral interfere com o normal neurodesenvolvimento, resultando no atraso ou regressão cognitivo-motora superior ao expectável para a patologia subjacente. ${ }^{4} \mathrm{O}$ atraso do desenvolvimento pode ser igualmente de

1. Serviço de Neurologia. Hospital Prof. Dr. Fernando Fonseca. Amadora. Portugal.

2. Serviço de Genética Médica. Hospital de Santa Maria. Centro Hospitalar e Universitário de Lisboa Norte. Lisboa. Portugal.

3. Unidade de Neuropediatria, Departamento de Pediatria. Hospital de Santa Maria. Centro Hospitalar e Universitário de Lisboa Norte. Lisboa. Portugal.

$\square$ Autor correspondente: Rita Martins. ritadossantosmartins@gmail.com

Recebido: 11 de julho de 2019 - Aceite: 30 de setembro de 2019| Copyright @ Ordem dos Médicos 2020 
uma manifestação da própria anomalia genética. ${ }^{4,5}$ Nestas síndromes, o pleiotropismo genético é significativo, não sendo possível estabelecer uma correlação directa entre genótipo e fenótipo. ${ }^{5-9}$ A mesma anomalia genética pode associar-se a fenótipos distintos e determinado fenótipo pode ser produzido por diferentes genes.

\section{MATERIAL E MÉTODOS}

Realizou-se uma revisão narrativa das EEl genéticas, com caracterização sindromática e fenotípica disponível até à data na literatura. Consultaram-se as publicações relevantes na PubMed, através da pesquisa dos termos chave 'epilepsia/epiléptica/encefalopatia/diagnóstico'. A informação sobre os principais genes envolvidos foi cruzada com a pesquisa nas bases de dados universais Online Mendelian Inheritance in Man database (OMIM), Human Gene Mutation Database (HGMD) e EpilesyGene referentes aos mesmos termos. Utilizou-se a classificação das epilepsias mais recente da International League Against Epilepsies (ILAE) na definição de EEl. ${ }^{4}$ A classificação das variantes genéticas baseou-se nas orientações do American College of Medical Genetics and Genomics (ACMG). ${ }^{10}$

Os principais grupos de EEI foram subdivididos em formas clássicas, síndromes genéticas específicas e cromossomopatias. Descreveram-se as principais técnicas genéticas. Por fim, os autores sistematizaram a investigação diagnóstica num algoritmo.

\section{RESULTADOS \\ Conceitos gerais}

Até 2001, a etiopatogenia das EEl era atribuída a um presumível insulto adquirido durante o desenvolvimento cerebral. Apenas nesta altura foi descoberta a primeira causa genética de EEI, nomeadamente na síndrome de Dravet por mutação do gene SCN1A. ${ }^{11}$ Desde então, as novas técnicas moleculares, tais como o microarray cromossómico e as técnicas de sequenciação de nova geração (SNG), conduziram à descoberta de novos genes e clarificação da fisiopatogenia implicada. ${ }^{12-15} \mathrm{Nas} \mathrm{EEI}$, as causas estruturais não são as mais frequentes. A excepção é a síndrome de West em que as causas estruturais são mais frequentes e correspondem a $30 \%$ dos casos. (ex. AVC perinatal e encefalopatia hipóxico-isquémica) ${ }^{16}$ No caso específico das malformações do desenvolvimento cortical (MDC), estas resultam de uma anormal interacção entre mutações somáticas do tecido cerebral e factores ambientais. ${ }^{17}$

Existem vários cenários genéticos possíveis nas $\mathrm{EEI},{ }^{18}$ incluindo variações citogenéticas estruturais (aneuploidias, cromossomas em anel, microdelecções, microduplicações), MDC (ex. LIS1, DCX, ARX), genes e loci cromossómicos associados a encefalopatias do neurodesenvolvimento (ex. síndrome de Rett por variantes nos MECP2, CDLK5, FOXG1, ARX) e genes e loci cromossómicos associados a síndromes epilépticas específicas (SCN1A na síndrome de Dravet, STXBP1 na síndrome de Ohtahara, CDKL5, SPTAN e MAGI2 na síndrome de West).
Genes implicados nas encefalopatias epilépticas infantis

Os genes envolvidos nas EEl desempenham funções muito distintas no sistema nervoso central. ${ }^{19}$ Estes relacionam-se com mecanismos de epileptogénese, incluindo a morfogénese tipo homeobox $(A R X)$, migração neuronal (ARX, TBC1D24, DEPDC5), sinaptogénese (STXBP1, PCHD19, MAGI2, PRRT2), função dendrítica (CDKL5, $K C N D 2)$, estrutura e função axonal (SPTAN1), função de interneurónios ( $A R X, S C N 1 A, G A B R G 2)$, regulação de canais iónicos dependentes de voltagem (SCN1A, SCN1B, SCN2A, SCN8A, KCNQ2, KCND2, KCNT1), receptores do ácido gama-aminobutírico (GABRG2), receptores do glutamato (GRIN2A, GRIN2B), regulação de neurotransmissores (STXBP1, PNPO), transcrição nuclear (CDLK5, MECP2, FOXG1, PLCß1, QARS), reparação de DNA $(P N K P)$, apoptose neuronal (SPTAN1), transporte membranar (SLC25A22, SLC2A1, AGC1) e regulação do DNA mitocondrial (POLG1), entre outros. Na Tabela 1 descrevem-se os principais genes descritos na literatura e respectivos fenótipos. ${ }^{19,20}$

\section{Caracterização fenotípica}

As EEl agrupam-se em função das características electroclínicas, idade de início, tipos de crises epilépticas, padrão ictal e interictal do EEG, manifestações clínicas e prognóstico. ${ }^{4,21}$ Vários factores contribuem para a sua heterogeneidade genética, incluindo a fase da embriogénese em que ocorre a mutação, factores epigenéticos e reguladores da expressão génica. ${ }^{5,18} \mathrm{O}$ espectro das EEl varia desde entidades benignas até encefalopatias neonatais graves, tal como demonstrado pelas canalopatias associadas aos genes KCNQ2, SCN1A e SCN2A. Por exemplo, variantes patogénicas do KCNQ2 podem causar a epilepsia benigna neonatal familiar autolimitada, em que os recém-nascidos desenvolvem uma salva de crises entre o segundo e terceiro dias de vida. A maioria evolui posteriormente com normal desenvolvimento e remissão da epilepsia. Esta apresenta hereditariedade autossómica dominante de elevada penetrância. ${ }^{22}$ No espectro oposto, mutações de novo no mesmo gene causam uma encefalopatia neonatal grave, ${ }^{23} \mathrm{com}$ crises tónicas e padrão surto-supressão, associada à síndrome de Ohtahara.

As variantes patogénicas do SCN1A podem ocorrer na síndrome de Dravet, na epilepsia generalizada com convulsões febris-plus (GEFS+) e na epilepsia migratória maligna do lactente. ${ }^{24} \mathrm{~A}$ GEFS+ é uma entidade autolimitada benigna que geralmente não carece de tratamento, ao contrário das restantes. Embora apenas $10 \%$ dos casos de síndrome de Dravet apresentem transmissão familiar autossómica dominante e a maioria se associe a mutações de novo missense ou truncadas, pode existir variabilidade fenotípica e penetrância incompleta na mesma família, com indivíduos assintomáticos e outros elementos afectados por GEFS+ ou por formas mais frustres Dravet-like.

A encefalopatia maligna com crises focais migratórias da infância apresenta uma evolução catastrófica, em que 
Tabela 1 - Fenótipos primariamente associados aos principais genes reportados na literatura

\begin{tabular}{|c|c|c|c|}
\hline$A R X$ & $\begin{array}{l}\text { Sd de Ohtahara, sd de West, encefalopatia } \\
\text { mioclónica, encefalopatia epiléptica discinética }\end{array}$ & PNPO & EEI neonatal \\
\hline$C D K L 5$ & $\begin{array}{l}\text { Espectro da sd de Rett, EEI precoce, sd de West, } \\
\text { epilepsia focal migratória maligna, espectro da sd } \\
\text { de Angelman, sd de Lennox-Gastaut }\end{array}$ & SCN1A & $\begin{array}{l}\text { Sd Dravet, epilepsia generalizada com convulsões } \\
\text { febris-plus, epilepsia focal migratória maligna }\end{array}$ \\
\hline SLC25A22 & $\begin{array}{l}\text { EEI precoce, sd de Ohtahara, epilepsia focal } \\
\text { migratória maligna }\end{array}$ & SCN1B & $\begin{array}{l}\text { Sd de Dravet, epilepsia focal criptogénica, } \\
\text { epilepsia generalizada com convulsões febris-plus }\end{array}$ \\
\hline STXBP1 & $\begin{array}{l}\text { Sd de Ohtahara, encefalopatia mioclónica, EEI } \\
\text { precoce, sd de West, epilepsia focal migratória } \\
\text { maligna, sd de Dravet, espectro da sd de Rett, sd } \\
\text { de Doose, sd de Lennox-Gastaut }\end{array}$ & SCN2A & $\begin{array}{l}\text { Sd de Dravet, epilepsia focal criptogénica, } \\
\text { epilepsia generalizada com convulsões febris-plus, } \\
\text { epilepsia focal migratória maligna, sd de Lennox- } \\
\text { Gastaut }\end{array}$ \\
\hline SPTAN1 & Sd de West, EEI precoce & SCN3A & EEI precoce, epilepsia focal criptogénica \\
\hline$P L C \beta$ & $\begin{array}{l}\text { EEI precoce, sd de West, epilepsia focal } \\
\text { migratória maligna }\end{array}$ & SCN8A & EEI precoce \\
\hline MAGI2 & EEI precoce, sd West & SCN9A & $\begin{array}{l}\text { Espectro da sd de Dravet, epilepsia generalizada } \\
\text { com convulsões febris-plus }\end{array}$ \\
\hline PNKP & Sd de Ohtahara, sd de West & PCHD19 & $\begin{array}{l}\text { Espectro da sd de Dravet, epilepsia com atraso } \\
\text { cognitivo na mulher, epilepsia focal migratória } \\
\text { maligna }\end{array}$ \\
\hline PIGA & Sd de Ohtahara, EEI precoce & GABRA1 & Espectro da sd de Dravet \\
\hline DEPDC5 & Displasia cortical, sd de West & GABRG2 & $\begin{array}{l}\text { Espectro da sd de Dravet, complexo autismo- } \\
\text { epilepsia }\end{array}$ \\
\hline KCNQ2 & $\begin{array}{l}\text { EEI precoce e neonatal, epilepsia neonatal } \\
\text { benigna }\end{array}$ & POLG1 & $\begin{array}{l}\text { Doença de Alpers, EEI precoce, epilepsia focal } \\
\text { migratória maligna }\end{array}$ \\
\hline TBC1D24 & $\begin{array}{l}\text { EEI precoce, epilepsia focal migratória maligna, } \\
\text { encefalopatia mioclónica }\end{array}$ & UBE3A & Sd de Angelman \\
\hline MECP2 & Sd de Rett & FOXG1 & Espectro da sd de Rett \\
\hline SLC25A12 & Sd de West, EEI precoce & $S L C 2 A 1$ & $\begin{array}{l}\text { Deficiência de GLUT-1, epilepsia de ausências } \\
\text { precoce e refractária, Sd de West, sd de Doose, } \\
\text { encefalopatia mioclónica }\end{array}$ \\
\hline PRRT2 & Epilepsia focal migratória maligna & ARHGEF9 & EEI precoce, complexo autismo-epilepsia \\
\hline CHD2 & $\begin{array}{l}\text { EEI precoce, epilepsia mioclónica, sd de Lennox- } \\
\text { Gastaut }\end{array}$ & GRIN2A & Sd de West, sd de Landau-Kleffner \\
\hline QARS & EEI precoce & GRIN2B & $\begin{array}{l}\text { Sd de West, epilepsia focal migratória maligna, sd } \\
\text { Lennox-Gastaut }\end{array}$ \\
\hline KCND2 & EEI precoce & KCNT1 & $\begin{array}{l}\text { Epilepsia focal migratória maligna, EEI precoce, } \\
\text { epilepsia familiar nocturna do lobo frontal }\end{array}$ \\
\hline
\end{tabular}

Sd: síndrome; EEl: encefalopatia epiléptica infantil

metade dos casos se associa a mutações de novo com ganho de função no gene do canal de potássio KCNT1. ${ }^{25,26}$ Mutações no mesmo gene herdadas ou de novo são identificadas em doentes com epilepsia nocturna do lobo frontal que cursa com crises frontais nocturnas, perturbação do desenvolvimento intelectual e alterações do comportamento. ${ }^{27}$ Noutro espectro igualmente distinto, variantes patogénicas no KCNT1 podem-se apresentar ainda como síndrome de Ohtahara ou de West. Na Tabela 2 descrevem-se os genes associados a EEl específicas..$^{5,19}$

\section{Caracterização genética}

A causa genética mais comum das EEl são mutações simples, associando-se menos frequentemente a anomalias cromossómicas ou mutações em genes implicados em MDC. Apenas uma reduzida fracção corresponde a erros hereditários do metabolismo. As encefalopatias metabólicas têm geralmente início no período neonatal, apresentação clínica grave e associam-se a outras manifestações sistémicas. Embora incomuns, por serem potencialmente tratáveis, devem ser sempre consideradas na investigação inicial de uma EEI precoce,$^{15}$ incluindo os defeitos genéticos de piridoxina associado aos genes ALDH7A1 e PNPO, do transportador GLUT-1 por variantes no $S L C 2 A,{ }^{28}$ os défices de creatina, de folatos e de serina, entre outros.

Nas EEl são mais frequentes as mutações de novo que 
Tabela 2 - Genes primariamente associados a determinadas síndromes epilépticas

Síndrome de Ohtahara
Encefalopatia mioclónica neonatal
Epilepsia focal migratória maligna
Encefalopatia mioclónica precoce e neonatal
EEl precoce

Síndrome de West

Síndrome de Dravet

Espectro da síndrome de Rett

Síndrome de Lennox-Gastaut

Complexo autismo-epilepsia

Espectro da síndrome de Angelman

Encefalopatia epiléptica discinética
STXBP1, KCNQ2, SCN2A, AARS, ARX, BRAT1, CACA2D, GNAO1, KCNT1, PIGA, PIGQ, SCN8A, SLC25A22

ERBB4, PIGA, SETBP1, SLC25A22

SLC25A22, TBC1D24, STXBP1, CDKL5, PLCB1, PCHD19, POLG1, SCN1A, SCN2A, SLC2A1, KCNT1

ARX, CDKL5, SLC25A22, SLC2A1, POLG1, CHD2, STXBP1

STXBP1, ARX, SPTAN1, SLC25A22, PLCB1, MAGI2, PNKP, KCNQ2, SLC2A1, POLG1, SCN2, SCN3A, SCN8A, PNPO, CHD2, GRIN2A, SLC25A12, ARHGEF9, KCNT1

STXBP1, ARX, CDKL5, FOXG1, SPTAN1, SLC25A22, PLCB1, MAGI2, PNKP, KCNQ2, SLC2A1, POLG1, AGC1, PNPO, SCN1A, SCN2A, SCN8A, KCND2, CHD2, HCN1, GRIN2A, GRIN2B

SCN1A, PCHD19, SCN1B, SCN2A, STXBP1, GABRG2, GABRB3, GABRA1, SCN9A

CDKL5, MECP2, FOCG1, UBE3A, STXBP1

CACNA1A, CDKL5, CHD2, GABRB3, GRIN2B, KCNQ3, SCN1A, SCN2A, SCN8A, STXBP1

ARX, CDKL5, MECP2, FOXG1, SCN1A, PCHD19, UBE3A, KCND2, AGC1, ARHGEF9, STXBP1

UBE3A, CDKL5, TC4

ARX, MEPC2, FOXG1, STXBP1, PNPO, SCN1A, TBC1D24, KCNQ2, SLC2A1, POLG1, PRRT2 podem ocorrer numa fase inicial da embriogénese ou nos gâmetas de um dos progenitores. ${ }^{29}$ As variantes implicadas são maioritariamente exónicas, embora exista evidência crescente do envolvimento de regiões do DNA não codificante. $O$ padrão de hereditariedade pode ser ligado ao $X$ (ex. $A R X$ ) ou dominante (ex. $D C X$ ). As formas autossómicas recessivas em homozigotia associam-se sobretudo a consanguinidade parental. Contudo, na ausência de consanguinidade deve-se considerar a possibilidade de heterozigotia composta com herança de duas variantes recessivas distintas pelos progenitores. O sexo feminino pode ser ainda exclusivamente afectado (ex. PCDH19).

$\mathrm{Na}$ investigação das EEI, outro conceito importante é o mosaicismo ${ }^{30,31}$ que corresponde a duas populações de células com constituição genética diferente coexistentes no mesmo indivíduo. ${ }^{32} \mathrm{O}$ mosacismo gonadal ocorre quando a variante está presente apenas nos gâmetas de um dos progenitores. Este é evidenciado quando o casal apresenta dois descendentes afectados pela mesma mutação, embora o estudo genético do DNA leucocitário seja normal. O mosaicismo somático ocorre durante a embriogénese e resulta em mutações numa linha somática específica. Encontra-se associado a alterações estruturais, tais como a hemimegalencefalia e outras anomalias corticais. ${ }^{33}$ Nestes casos, pode ser útil realizar estudo genético em fibroblastos (biópsia de pele), embora nem sempre seja possível provar o mosaicismo.

\section{Encefalopatias epilépticas infantis genéticas}

As síndromes epilépticas genéticas podem ser agrupadas em EEl clássicas, síndromes genéticas específi- cas e cromossomopatias. Contudo, importa salientar que um número substancial de encefalopatias não apresenta características distintivas. Este grupo complexo tem sido progressivamente elucidado à medida que novas entidades são descritas. As encefalopatias por erros hereditários do metabolismo não são do âmbito deste artigo.

\section{Encefalopatias epilépticas infantis clássicas \\ 1. Encefalopatias epilépticas com padrão surto-supres- são}

Síndrome de Ohtahara: A síndrome de Ohtahara é rara e de prognóstico grave, apresentando crises tónicas isoladas ou em salvas no período neonatal. ${ }^{34} \mathrm{O}$ EEG interictal caracteriza-se por um padrão surto-supressão. ${ }^{35}$ As principais etiologias são as alterações estruturais, erros hereditários do metabolismo e anomalias genéticas. A mortalidade é elevada e a deterioração clínica com evolução para síndrome de West e/ou Lennox-Gastaut é expectável em caso de sobrevivência. Vários genes têm sido associados, nomeadamente STXBP1, ARX, SLC24A22 e KCNQ2.

Encefalopatia mioclónica precoce: A encefalopatia mioclónica precoce surge igualmente no período neonatal e apresenta prognóstico grave, cursando com crises mioclónicas multifocais. ${ }^{28,35}$ O EEG interictal apresenta um padrão de surto-supressão. Associa-se sobretudo a erros hereditários do metabolismo, incluindo hiperglicinémia não cetótica, acidémias orgânicas e deficiência de co-factor de molibdénio. Foram reportados raros casos por variantes patogénicas envolvendo o gene SLC25A22.

Espasmos infantis e síndrome de West: Os espasmos infantis surgem geralmente entre os quatro e seis 
meses de idade. A síndrome de West corresponde à tríade de espasmos epiléticos, regressão psicomotora e padrão interictal de hipsarritmia (actividade epileptiforme multifocal de grande voltagem e lentificação generalizada). ${ }^{36}$ Os espasmos surgem tipicamente em salvas na transição sono-vigília. Podem ser criptogénicos, de causa estrutural, metabólica ou genética. Múltiplos genes têm sido descritos, tais como o STXBP1, ARX e CDKL5.

Síndrome de Dravet: A síndrome de Dravet ou encefalopatia mioclónica da infância caracteriza-se por crises febris prolongadas tónico-clónicas e/ou hemiclónicas com início até aos 18 meses de vida. ${ }^{37}$ Podem ainda ocorrer crises mioclónicas e ausências atípicas, entre outras crises. Embora o desenvolvimento seja inicialmente normal, a deterioração cognitiva ocorre até aos quatro anos de idade. O EEG inicial pode ser normal, evoluindo para lentificação generalizada da electrogénese. ${ }^{38} \mathrm{Em}$ mais de $80 \%$ dos casos, corresponde a uma canalopatia por mutação de novo no gene SCN1A. O mesmo gene associa-se ainda a GEFS+e, menos frequentemente, a epilepsia migratória maligna do lactente. Outros genes descritos em doentes com síndrome Dravet-like incluem o PCHD19, GABRA1 e GABRG2.

Síndrome de Lennox-Gastaut: A síndrome de Lennox-Gastaut geralmente tem início entre os três e cinco anos de idade. Caracteriza-se por vários tipos de crises, nomeadamente crises tónicas, atónicas, tónico-clónicas, mioclónicas e ausências atípicas. ${ }^{39} \mathrm{O}$ EEG interictal apresenta paroxismos de actividade rápida e complexos generalizados de ponta-onda lenta $(<2,5 \mathrm{~Hz})$. Evolui com grave perturbação do desenvolvimento intelectual. A epilepsia é fármaco-resistente, persistindo na idade adulta em $80 \%$ dos casos. Embora seja sobretudo de causa estrutural, vários genes (ex. SCN2A, CDKL5, STXBP1) e variações do número de cópias (ex. microduplicação 15q11-q13) têm sido descritos. ${ }^{1}$ Todavia, o seu perfil genético ainda é desconhecido.

\section{Síndromes genéticas específicas}

Esclerose Tuberosa: A esclerose tuberosa é uma doença autossómica dominante com envolvimento cutâneo, cardíaco, renal e do sistema nervoso central..$^{40} \mathrm{O}$ diagnóstico assenta em critérios clínicos e na identificação de variante patogénica nos genes TSC1 ou TSC2. A principal manifestação neurológica é a epilepsia, afectando até $90 \%$ dos doentes. Um terço das crianças desenvolve espasmos epilépticos. ${ }^{41}$ Embora a sua gravidade se correlacione com o número, localização e tamanho dos túberes corticais, foram reportados casos com epilepsia sem alterações estruturais encefálicas, bem como com túberes sem efeito epileptogénico. ${ }^{42-44}$

Síndrome de Rett: A síndrome de Rett caracteriza-se por regressão do desenvolvimento a partir dos seis meses de idade, microcefalia pós-natal, estereotipias manuais e epilepsia. ${ }^{45} \mathrm{Na}$ sua forma clássica, o sexo feminino é atingido por uma variante em heterozigotia no gene MECP2 localizado no cromossoma $\mathrm{X}^{46}$. Mais recentemente, foram descritas encefalopatias epilépticas neonatais graves por variantes no MECP2 no sexo masculino. A forma congénita da síndrome de Rett associada a variante no gene FOXG1 afecta ambos os sexos e também pode apresentar epilepsia refractária. ${ }^{47}$ Existem ainda outros genes associados a fenótipos Rett-like, tais como o STXBP1, ZNF238 e EEF1A2. ${ }^{48}$

Síndrome de Angelman: A síndrome de Angelman caracteriza-se por atraso cognitivo-motor, natureza afectiva, ataxia, epilepsia e dismorfias sugestivas. ${ }^{49}$ O EEG interictal apresenta actividade delta trifásica de predomínio frontal..$^{50}$ Diferentes mecanismos genéticos associam-se a anormal expressão da cópia materna do gene $U B E 3 A$, a referir, delecção da região crítica 15q11.2-q13 no cromossoma materno $(60 \%-75 \%)$, dissomia uniparental paterna $(2 \%-5 \%)$, defeito de imprinting ( $2 \%$ - $5 \%$ ) e mutação no próprio gene (10\%). Em $85 \%$ dos casos associa-se a epilepsia que apresenta gravidade variável.

Síndrome de Pitt-Hopkins: A síndrome de Pitt-Hopkins caracteriza-se por atraso cognitivo-motor, fácies distintiva, alterações respiratórias e epilepsia, entre outras características. ${ }^{51} \mathrm{Em}$ metade dos casos a epilepsia surge precocemente. O EEG é composto por complexos pseudoperiódicos nas regiões do vértex e occipitais. ${ }^{52}$ Está associada a delecções ou mutações de novo no gene TCF4.

Síndrome de Mowat-Wilson: A síndrome de Mowat-Wilson caracteriza-se por atraso cognitivo-motor, microcefalia, doença de Hirschpung, dismorfias distintivas e outras malformações congénitas. Cursa frequentemente com epilepsia refractária precoce, destacando-se crises motoras e ausências atípicas. ${ }^{53}$ Está associada a delecções, translocações ou mutações intragénicas em heterozigotia no gene ZEB2.

\section{Anomalias cromossómicas}

Algumas anomalias cromossómicas estão associadas a síndromes específicas, tais como a síndrome de West. São exemplos a trissomia 21 , cromossoma 20 e cromossoma 14 em anel, síndrome de inversão do cromossoma 15 e a monossomia 1 p36.

\section{Testes genéticos nas encefalopatias epilépticas infan-} tis

O repertório de testes disponíveis é vasto e complexo (Tabela 3). A marcha diagnóstica deve ser sistematizada e conscienciosa das limitações de cada técnica.

\section{Microarray cromossómico}

As variações de número de cópias (VNC) são delecções ou duplicações de segmentos do DNA. A patogenicidade das VNC de grande dimensão é amplamente reconhecida na literatura. ${ }^{54}$ Contudo, a capacidade de detecção de VNC de pequena dimensão tornou-se recentemente possível através das técnicas de array-comparative genomic hybridization (array-CGH) e array-single nucleotide polymorphism (array-SNP), conjuntamente designadas de microarray cromossómico (MAC). Este deve ser considerado na investigação inicial do doente, sobretudo se existirem alterações dismórficas ou polimalformativas. ${ }^{55} \mathrm{O}$ MAC 
Tabela 3 - Testes genéticos na investigação das encefalopatias epilépticas

\begin{tabular}{|c|c|c|c|}
\hline Teste genético & Detecção & Duração aproximada & Indicações \\
\hline $\begin{array}{l}\text { Microarray cromossómico } \\
\text { - array CGH e SNP }\end{array}$ & Variações de número de cópias & 28 dias & $\begin{array}{l}\text { Estudo inicial da epilepsia, sobretudo } \\
\text { se associada a dismorfias ou alterações } \\
\text { polimalformativas }\end{array}$ \\
\hline Cariótipo & $\begin{array}{l}\text { Anomalias cromossómicas } \\
\text { major }\end{array}$ & 18 dias & $\begin{array}{l}\text { Suspeita de síndrome de cromossoma } \\
20 \text { em anel }\end{array}$ \\
\hline Estudo dirigido do gene & $\begin{array}{l}\text { Alterações na sequência de } \\
\text { bases, duplicações e delecções }\end{array}$ & 2 a 6 semanas & $\begin{array}{l}\text { Fenótipo fortemente sugestivo de } \\
\text { síndrome monogénica }\end{array}$ \\
\hline Painel multigénico & $\begin{array}{l}\text { Alterações na sequência de } \\
\text { bases por SNG de genes } \\
\text { incluídos }\end{array}$ & 3 a 6 semanas & $\begin{array}{l}\text { Vários genes estabelecidos para } \\
\text { determinada síndrome ou fenótipo }\end{array}$ \\
\hline Sequenciação de exoma & $\begin{array}{l}\text { Alterações na sequência de } \\
\text { bases por SNG da região } \\
\text { codificante do genoma }\end{array}$ & 8 a 12 semanas & $\begin{array}{l}\text { Síndrome epiléptica sem genótipo } \\
\text { específico } \\
\text { Em trio preferível para estudo de } \\
\text { variantes de novo }\end{array}$ \\
\hline Sequenciação de genoma & $\begin{array}{l}\text { Alterações na sequência de } \\
\text { bases por SNG de todo o } \\
\text { genoma }\end{array}$ & 8 a 12 semanas & $\begin{array}{l}\text { Casos selecionados com estudo de } \\
\text { exoma negativo }\end{array}$ \\
\hline
\end{tabular}

permite identificar VNC superiores a $20 \mathrm{~Kb}$, não detectáveis pela técnica SNG.

\section{Técnicas de sequenciação de nova geração}

A SNG substituiu grandemente a tradicional sequenciação de Sanger em diversas áreas, incluindo a epilepsia. Ao contrário da técnica Sanger, a SNG permite a sequenciação simultânea de milhões de fragmentos de DNA ( 20.000 genes), tornando exequível a sequenciação completa do exoma num período de algumas semanas. ${ }^{14}$ As duas aplicações mais comuns são os painéis multigénicos e a sequenciação de exoma.

\section{Painéis multigénicos}

Os painéis multigénicos testam variantes de sequência, delecções e duplicações em genes selecionados, representando um método útil quando vários genes são potenciais causadores da doença ou fenótipo em estudo. ${ }^{56,57} \mathrm{O}$ número de genes incluídos e as características fenotípicas de cada painel são variáveis entre laboratórios. Para uma selecção criteriosa, deve-se primeiro determinar se o fenótipo do doente corresponde ao do painel requisitado, ${ }^{58}$ por exemplo, encefalopatias epilépticas, epilepsias mioclónicas progressivas e epilepsias metabólicas. A técnica de sequenciação utilizada nos painéis difere da de exoma, apresentando diferentes taxas de cobertura na detecção de variantes.

\section{Sequenciação de exoma}

A sequenciação de exoma analisa toda a região codificante do genoma humano. Perante a detecção de uma variante nova, não descrita no fenótipo, o estudo dos progenitores é necessário. A sequenciação do exoma em trio (doente e pais biológicos) pode ser uma abordagem inicial útil, dado que as EEI ocorrem mais frequentemente de novo. Estima-se que a sequenciação de exoma tenha uma rentabilidade diagnóstica de $25 \%$, atingindo os $50 \%$ quando aplicada em trio. ${ }^{56}$ Importa salientar que as variantes identificadas são classificadas em cinco classes (benignas, provavelmente benignas, de significado clínico incerto, provavelmente patogénicas ou patogénicas), segundo as guidelines do American College of Medical Genetics and Genomics (ACMG) . ${ }^{10}$

\section{Sequenciação específica de um gene}

O estudo específico de um gene pode ser ainda bastante útil nas epilepsias monogénicas mendelianas dada a relação genótipo-fenótipo linear, ${ }^{59}$ tais como, a síndrome de Dravet e a epilepsia neonatal benigna. Todavia, este não é o cenário mais frequente dada a elevada heterogeneidade das EEI. Os painéis multigénicos apresentam uma rentabilidade diagnóstica superior, estimada em 46\%, comparativamente a $15 \%$ no estudo dirigido do gene. ${ }^{56}$

\section{Outros}

A análise do cariótipo foi em grande parte substituída pelo MAC. Contudo, este é necessário no diagnóstico de algumas síndromes cromossómicas raras, tais como a síndrome do cromossoma $20 \mathrm{em}$ anel. A aplicabilidade de outras técnicas como fluorescence in situ hybridization (FISH) e multiplex ligation-dependent probe amplification (MLPA) nas EEI é limitada, todavia devem ser consideradas se existirem alterações dismórficas. ${ }^{60}$

\section{Desafios na interpretação dos resultados genéticos}

As variantes genéticas podem ser VNC ou de alterações de nucleótidos. A interpretação das variantes identificadas depende da sua frequência populacional, da presença nas bases de dados de doença e da associação com o fenótipo em estudo. ${ }^{10}$ Principalmente nas variantes de significado clínico incerto é necessário realizar o estudo genético nos pais. Na sua interpretação deve-se ter em conta a 
possibilidade de penetrância incompleta e variabilidade fenotípica. O estudo dos pais e a segregação familiar de variantes devem ser criteriosamente realizados em âmbito de consulta de Genética Médica.

\section{Algoritmo diagnóstico: abordagem ao estudo genético} das encefalopatias epilépticas infantis

A investigação das EEI genéticas deve seguir linhas de orientação apropriadas, contudo actualmente não existem recomendações internacionais consensuais. Deste modo, propomos o seguinte algoritmo diagnóstico (Fig. 1).

A ILAE recomenda a realização de estudo genético em todos os doentes com encefalopatias epilépticas. ${ }^{61} \mathrm{Em}$ primeiro lugar, deve-se obter uma história clínica detalhada com destaque para a gravidez e período perinatal. Por exemplo, uma história de movimentos fetais excessivos deve fazer suspeitar de crises epilépticas fetais, tal como observado nas encefalopatias pirodoxina-dependentes. A avaliação clínica é completada com um exame neurológico judicioso, ressonância magnética (RM) cranioencefálica e EEG em vigília e sono idealmente com registo de crises. Em segundo lugar, devemos determinar qual o fenótipo da criança com base no sexo, idade de início, tipos de crises, relação com estadio do sono, padrão electrográfico ictal/ interictal e outras manifestações clínicas. Na maioria dos casos é possível definir de antemão uma EEI específica e, a partir daí, considerar quais as causas genéticas mais frequentemente associadas. Se estas características electroclínicas forem inespecíficas, devemos ainda considerar determinados aspectos na RM cranioencefálica que podem auxiliar na pesquisa de genes envolvidos em MDC, tais como o $A R X$.

Embora representem apenas $5 \%$ das EEI, as epilepsias metabólicas hereditárias potencialmente tratáveis devem ser prontamente diagnosticadas. Uma avaliação laboratorial metabólica básica no sangue e urina deve ser sempre realizada, particularmente dirigida à deficiência de piridoxina e défice de GLUT-1 (também com estudo de líquor). Outras entidades como a deficiência de co-factor de molibdénio, acidúria orgânica e aminoacidopatias podem cursar com encefalopatias neonatais mioclónicas graves que carecem de investigação metabólica apropriada.

Após determinar o fenótipo do doente, se este for fortemente sugestivo de uma síndrome monogénica (ex: síndrome de Dravet), pode-se justificar a realização do estudo dirigido do gene. Todavia, se não for indicativo de uma

Encefalopatias epilépticas e do neurodesenvolvimento

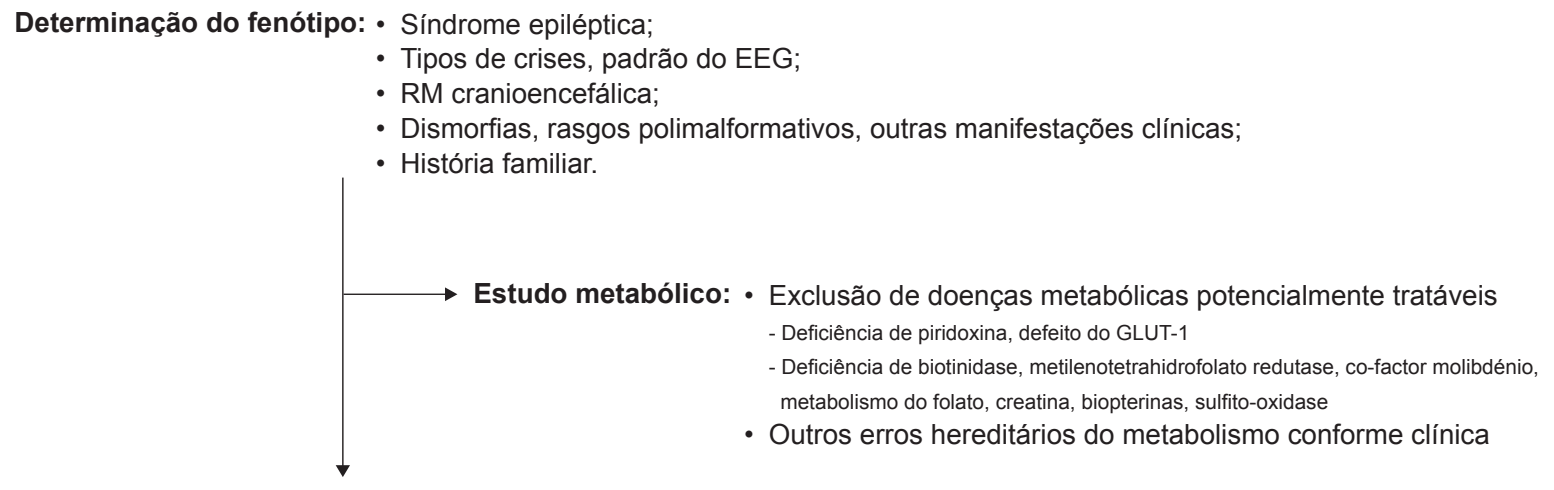

Fenótipo sugestivo de uma síndrome genética específica?

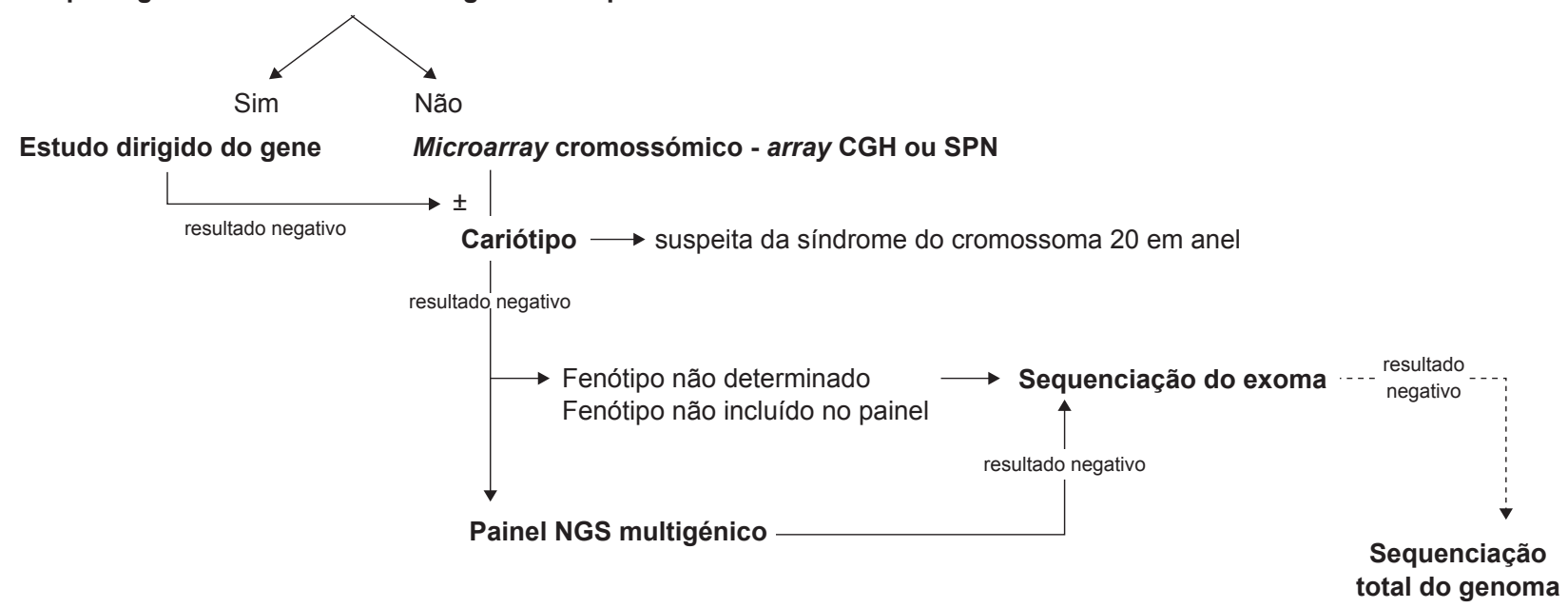

Figura 1 - Algoritmo diagnóstico para estudo das encefalopatias epilépticas infantis 
Tabela 4 - Síndromes genéticas epilépticas com potenciais implicações terapêuticas

\begin{tabular}{|c|c|c|}
\hline Gene & Clínica & Alteração terapêutica \\
\hline SCN1A & Síndrome de Dravet & Evitar bloqueadores dos canais de sódio \\
\hline$S C N 2 A$ & $\begin{array}{l}\text { Epilepsia parcial migratória maligna; } \\
\text { Encefalopatia infantil precoce; Dravet-like; } \\
\text { atraso intelectual isolado }\end{array}$ & Fenitoína pode ser eficaz \\
\hline SCN8A & Encefalopatia infantil precoce & Fenitoína pode ser eficaz \\
\hline$S L C 2 A 1$ & Défice de GLUT-1 & Dieta cetogénica indicada, triheptanoína em estudo \\
\hline KCNT1 & $\begin{array}{l}\text { Epilepsia focal migratória maligna, EEI } \\
\text { precoce }\end{array}$ & Quinidina pode ser eficaz \\
\hline PRRT2 & $\begin{array}{l}\text { Epilepsia focal neonatal } \\
\text { Discinésias paroxísticas, ataxia episódica }\end{array}$ & Carbamazepina pode ser eficaz \\
\hline ALDH7A1, PNPO & Encefalopatia infantil precoce & Piridoxina ou piridoxal fosfato indicados \\
\hline TSC1, TSC2 & Esclerose tuberosa & $\begin{array}{l}\text { Vigabatrina } \\
\text { Everolimus pode ser indicado }\end{array}$ \\
\hline
\end{tabular}

entidade genética específica, deve-se realizar a análise de MAC, sobretudo se existirem características dismórficas ou rasgos polimalformativos. O estudo do cariótipo está indicado na suspeita de uma síndrome cromossómica particular, por exemplo, síndrome do cromossoma 20 em anel, trissomia 21 e trissomia 18.

Se o MAC for negativo e/ou não existirem elementos físicos distintivos, o próximo passo devem ser os painéis multigénicos ou a sequenciação de exoma. Existem várias considerações relativas à selecção de painéis multigénicos: fenótipo (existe um painel específico?), gravidade (o diagnóstico célere tem impacto em decisões futuras?) e custo. Se existir um painel correspondente ao fenótipo do doente, é razoável realizá-lo como estudo seguinte. Contudo, se este não for dirigido ao fenótipo ou se não for possível decidir entre os painéis disponíveis, é razoável prosseguir com a sequenciação de exoma dada a relação rentabilidade-custo. Por fim, se o MAC e painéis não forem positivos, a sequenciação de exoma é o último passo, destacando-se a análise em trio para avaliação de variantes de novo. A sequenciação total do genoma já se realiza em casos selecionados com estudo de exoma negativo, prevendo-se que num futuro próximo venha a ser frequentemente aplicável na prática clínica.

Na marcha diagnóstica, sobretudo na sequenciação de exoma e genoma, o aconselhamento genético é imprescindível, dado o risco de detecção de variantes de significado incerto e achados incidentais com implicações para o doente e família. Deve ser realizado um consentimento informado por escrito específico para estas situações. O estudo genético pode ser condicionado por questões inerentes ao respectivo hospital, sendo fundamental a discus- são multidisciplinar (Neurologia, Genética e laboratório de Genética).

\section{Potenciais riscos e benefícios}

O diagnóstico genético apresenta implicações diagnósticas, prognósticas e terapêuticas. Este permite uma adequada orientação terapêutica, ${ }^{62}$ no que respeita a antiepilépticos aconselhados e terapêuticas dirigidas (Tabela 4). Por fim, salientamos o papel indispensável do aconselhamento familiar e opções reprodutivas, devendo-se ter sempre em consideração o impacto que o diagnóstico genético pode exercer sobre o doente e família.

\section{CONCLUSÃO}

Nos últimos anos, assistimos a uma notória expansão de conhecimentos sobre a etiopatogénese genética das EEI. Consequentemente, a sua marcha diagnóstica tornou-se complexa na prática clínica. O pleiotropismo e heterogeneidade genética não permitem estabelecer uma correlação linear entre genótipo e fenótipo. Deste modo, é necessária uma abordagem sistematizada com orientação dos testes genéticos adequados e outros estudos adicionais. O diagnóstico genético das EEI é crucial, dadas as suas implicações terapêuticas, prognósticas e de aconseIhamento familiar.

\section{CONFLITOS DE INTERESSE}

Os autores declaram não ter conflitos de interesse.

\section{FONTES DE FINANCIAMENTO}

Não foi solicitada qualquer fonte de financiamento. os autores não apresentam conflitos de interesse.

\section{REFERÊNCIAS}

1. Allen AS, Berkovic SF, Cossette P, Delanty N, Dlugos D, Eichler $E E$, et al. De novo mutations in epileptic encephalopathies. Nature. 2013;501:217-21
2. Nordli DR. Epileptic encephalopathies in infants and children. J Clin Neurophysiol. 2012;29:420-4.

3. Gürsoy S, Erçal D. Diagnostic approach to genetic causes of early-onset 
epileptic encephalopathy. J Child Neurol. 2016;31:523-32.

4. Scheffer IE, Berkovic S, Capovilla G, Connolly MB, French J, Guilhoto $\mathrm{L}$, et al. ILAE classification of the epilepsies: position paper of the ILAE Commission for Classification and Terminology. Epilepsia. 2017;58:51221.

5. McTague A, Howell KB, Cross JH, Kurian MA, Scheffer IE. The genetic landscape of the epileptic encephalopathies of infancy and childhood. Lancet Neurol. 2016;15:304-16.

6. Miceli F, Soldovieri MV, Ambrosino P, Barrese V, Migliore M, Cilio MR, et al. Genotype-phenotype correlations in neonatal epilepsies caused by mutations in the voltage sensor of Kv7.2 potassium channel subunits. Proc Natl Acad Sci USA. 2013;110:4386-91.

7. Orhan G, Bock M, Schepers D, Ilina El, Reichel SN, Löffler H, et al. Dominant-negative effects of KCNQ2 mutations are associated with epileptic encephalopathy. Ann Neurol. 2014;75:382-94.

8. Nakamura K, Kato M, Osaka H, Yamashita S, Nakagawa E, Haginoya $\mathrm{K}$, et al. Clinical spectrum of SCN2A mutations expanding to Ohtahara syndrome. Neurology. 2013;81:992-8.

9. Singh NA, Pappas C, Dahle EJ, Claes LR, Pruess TH, De Jonghe $P$, et al. A role of SCN9A in human epilepsies, as a cause of febrile seizures and as a potential modifier of Dravet syndrome. PLoS Genet. 2009;5:e1000649.

10. Richards S, Aziz N, Bale S, Bick D, Das S, Gastier-Foster J, et al. Standards and guidelines for the interpretation of sequence variants: a joint consensus recommendation of the American College of Medical Genetics and Genomics and the Association for Molecular Pathology. Genet Med. 2015;17:405-24.

11. Berg AT, Berkovic SF, Brodie MJ, Buchhalter J, Cross JH, Van Emde Boas $W$, et al. Revised terminology and concepts for organization of seizures and epilepsies: report of the ILAE Commission on Classification and Terminology, 2005-2009. Epilepsia. 2010;51:676-85.

12. Veeramah $K R$, Johnstone $L$, Karafet $T M$, Wolf $D$, Sprissler R, Salogiannis $\mathrm{J}$, et al. Exome sequencing reveals new causal mutations in children with epileptic encephalopathies. Epilepsia. 2013;54:1270-81.

13. Hildebrand MS, Dahl HH, Damiano JA, Smith RJ, Scheffer IE, Berkovic SF. Recent advances in the molecular genetics of epilepsy. J Med Genet. 2013;50:271-9.

14. Møller RS, Dahl HA, Helbig I. The contribution of next generation sequencing to epilepsy genetics. Expert Rev Mol Diagn. 2015;15:15318.

15. Sharma S, Prasad A. Genetic testing of epileptic encephalopathies of infancy: an approach. Can J Neurol Sci. 2013;40:10-6.

16. Osborne JP, Lux AL, Edwards SW, Hancock E, Johnson AL, Kennedy $\mathrm{CR}$, et al. The underlying etiology of infantile spasms (West syndrome): information from the United Kingdom Infantile Spasms Study (UKISS) on contemporary causes and their classification. Epilepsia. 2010;51:216874.

17. Guerrini R. Genetic malformations of the cerebral cortex and epilepsy. Epilepsia. 2005;46:32-37.

18. Mastrangelo M, Leuzzi V. Genes of early-onset epileptic encephalopathies: from genotype to phenotype. Pediatr Neurol. 2012;46:24-31.

19. Wang J, Lin ZJ, Liu L, Xu HQ, Shi YW, Yi YH, et al. Epilepsy-associated genes. Seizure. 2017;44:11-20.

20. Anney RJ, Avbersek A, Balding D, Baum L, Becker F, Berkovic SF, et al. Genetic determinants of common epilepsies: A meta-analysis of genome-wide association studies. Lancet Neurol. 2014;13:893-903.

21. Khan S, Al Baradie R. Epileptic encephalopathies: an overview. Epilepsy Res Treat. 2012;2012:1-8.

22. Singh NA, Westenskow P, Charlier C, Pappas C, Leslie J, Dillon J, et al. KCNQ2 and KCNQ3 potassium channel genes in benign familial neonatal convulsions: expansion of the functional and mutation spectrum. Brain. 2003;126:2726-37.

23. Weckhuysen S, Mandelstam S, Suls A, Audenaert D, Deconinck T, Claes LR, et al. KCNQ2 encephalopathy: emerging phenotype of a neonatal epileptic encephalopathy. Ann Neurol. 2012;71:15-25.

24. Scheffer IE, Zhang YH, Jansen FE, Dibbens L. Dravet syndrome or genetic (generalized) epilepsy with febrile seizures plus? Brain Dev. 2009;31:394-400.

25. Coppola G, Plouin P, Chiron C, Robain O, Dulac O. Migrating partial seizures in infancy: a malignant disorder with developmental arrest. Epilepsia. 1995;36:1017-24.

26. Ohba C, Kato M, Takahashi N, Osaka H, Shiihara T, Tohyama J, et al. De novo KCNT1 mutations in early-onset epileptic encephalopathy. Epilepsia. 2015;56:e121-8.
27. Derry CP, Heron SE, Phillips F, Howell S, MacMahon J, Phillips HA, et al. Severe autosomal dominant nocturnal frontal lobe epilepsy associated with psychiatric disorders and intellectual disability. Epilepsia. 2008;49:2125-9.

28. Mastrangelo $M$, Celato $A$, Leuzzi V. A diagnostic algorithm for the evaluation of early onset genetic-metabolic epileptic encephalopathies. Eur J Paediatr Neurol. 2012;16:179-91.

29. Vadlamudi L, Dibbens LM, Lawrence KM, Iona X, McMahon JM, Murrell W, et al. Timing of de novo mutagenesis - a twin study of sodium-channel mutations. N Engl J Med. 2010;363:1335-40.

30. Depienne C, Trouillard O, Gourfinkel-An I, Saint-Martin C, Bouteiller D, Graber D, et al. Mechanisms for variable expressivity of inherited SCN1A mutations causing Dravet syndrome. J Med Genet. 2010;47:404-10.

31. Morimoto M, Mazaki E, Nishimura A, Chiyonobu T, Sawai $Y$, Murakami A, et al. SCN1A mutation mosaicism in a family with severe myoclonic epilepsy in infancy. Epilepsia. 2006;47:1732-6.

32. Poduri A, Evrony GD, Cai X, Walsh CA. Somatic mutation, genomic variation, and neurological disease. Science. 2013;341:1237758.

33. Lee JH, Huynh M, Silhavy JL, Kim S, Dixon-Salazar T, Heiberg A, et al. De novo somatic mutations in components of the PI3K-AKT3-mTOR pathway cause hemimegalencephaly. Nat Genet. 2012;44:941-5.

34. Beal JC, Cherian K, Moshe SL. Early-onset epileptic encephalopathies: Ohtahara syndrome and early myoclonic encephalopathy. Pediatr Neurol. 2012;47:317-23.

35. Ohtahara S, Yamatogi Y. Epileptic encephalopathies in early infancy with suppression-burst. J Clin Neurophysiol. 2003;20:398-407.

36. Trevathan E, Murphy CC, Yeargin-Allsopp M. The descriptive epidemiology of infantile spasms among Atlanta children. Epilepsia. 1999;40:748-51.

37. Dravet C. The core Dravet syndrome phenotype. Epilepsia. 2011;52:S39.

38. Wolff M, Cassé-Perrot C, Dravet C. Severe myoclonic epilepsy of infants (Dravet syndrome): Natural history and neuropsychological findings. Epilepsia. 2006;47:S45-8.

39. Gastaut H, Roger J, Soulayrol R, Tassinari CA, Régis H, Dravet C, et al. Childhood epileptic encephalopathy with diffuse slow Spike-Waves (otherwise known as "Petit Mal Variant") or Lennox syndrome. Epilepsia. 1966;7:139-79.

40. Osborne JP, Fryer A, Webb D. Epidemiology of tuberous sclerosis. Ann N Y Acad Sci. 1991;615:125-7.

41. Kassiri J, Snyder TJ, Bhargava R, Wheatley BM, Sinclair DB. Cortical tubers, cognition, and epilepsy in tuberous sclerosis. Pediatr Neurol. 2011;44:328-32

42. Boronat S, Shaaya EA, Doherty CM, Caruso P, Thiele EA. Tuberous sclerosis complex without tubers and subependymal nodules: a phenotype-genotype study. Clin Genet. 2014;86:149-154.

43. Wu WE, Kirov II, Tal A, Babb JS, Milla S, Oved J, et al. Brain MR spectroscopic abnormalities in "MRI-negative" tuberous sclerosis complex patients. Epilepsy Behav. 2013;27:319-25.

44. Jansen FE, Vincken KL, Algra A, Anbeek P, Braams O, Nellist M, et al. Cognitive impairment in tuberous sclerosis complex is a multifactorial condition. Neurology. 2008;70:916-23.

45. Glaze DG, Percy AK, Skinner S, Motil KJ, Neul JL, Barrish JO, et al. Epilepsy and the natural history of Rett syndrome. Neurology. 2010;74:909-12.

46. Ramocki MB, Tavyev YJ, Peters SU. The MECP2 duplication syndrome. Am J Med Genet A. 2010;152A:1079-88.

47. Kortüm F, Das S, Flindt M, Morris-Rosendahl DJ, Stefanova I, Goldstein A, et al. The core FOXG1 syndrome phenotype consists of postnatal microcephaly, severe mental retardation, absent language, dyskinesia, and corpus callosum hypogenesis. J Med Genet. 2011;48:396-406.

48. Lopes F, Barbosa M, Ameur A, Soares G, De Sá J, Dias Al, et al. Identification of novel genetic causes of Rett syndrome-like phenotypes. J Med Genet. 2016;53:190-9.

49. Williams CA. Neurological aspects of the Angelman syndrome. Brain Dev. 2005;27:88-94.

50. Boyd SG, Harden A, Patton MA. The EEG in early diagnosis of the Angelman (Happy Puppet) syndrome. Eur J Pediatr. 1988;147:508-13.

51. Marangi G, Ricciardi S, Orteschi D, Lattante S, Murdolo M, Dallapiccola $B$, et al. The Pitt-Hopkins syndrome: report of 16 new patients and clinical diagnostic criteria. Am J Med Genet Part A. 2011;155:1536-45.

52. Zankl A, Addor MC, Maeder-Ingvar M, Schorderet DF. A characteristic EEG pattern in 4p-syndrome: case report and review of the literature. Eur J Pediatr. 2001;160:123-7.

53. Adam MP, Schelley S, Gallagher R, Brady AN, Barr K, Blumberg B, et al. 
Clinical features and management issues in Mowat-Wilson syndrome. Am J Med Genet Part A. 2006;140:2730-41.

54. Itsara A, Cooper GM, Baker C, Girirajan S, Li J, Absher D, et al Population analysis of large copy number variants and hotspots of human genetic disease. Am J Hum Genet. 2008;84:148-61.

55. Miller DT, Adam MP, Aradhya S, Biesecker LG, Brothman AR, Carter NP, et al. Consensus Statement: Chromosomal Microarray Is a First-Tier Clinical Diagnostic Test for Individuals with Developmental Disabilities or Congenital Anomalies. Am J Hum Genet. 2010;86:749-64.

56. Weber YG, Biskup S, Helbig KL, Von Spiczak S, Lerche H. The role of genetic testing in epilepsy diagnosis and management. Expert Rev Mol Diagn. 2017;17:739-50

57. Chambers C, Jansen LA, Dhamija R. Review of commercially available epilepsy genetic panels. J Genet Couns. 2016;25:213-7.
58. Poduri A, Sheidley BR, Shostak S, Ottman R. Genetic testing in the epilepsies-developments and dilemmas. Nat Rev Neurol. 2014;10:2939.

59. Ream MA, Patel AD. Obtaining genetic testing in pediatric epilepsy. Epilepsia. 2015;56:1505-14

60. Noh GJ, Jane Tavyev Asher Y, Graham JM. Clinical review of genetic epileptic encephalopathies. Eur J Med Genet. 2012;55:281-98.

61. Wilmshurst JM, Gaillard WD, Vinayan KP, Tsuchida TN, Plouin P, Van Bogaert $P$, et al. Summary of recommendations for the management of infantile seizures: Task Force Report for the ILAE Commission of Pediatrics. Epilepsia. 2015;56:1185-97.

62. Thomas RH, Berkovic SF. The hidden genetics of epilepsy - a clinically important new paradigm. Nat Rev Neurol. 2014;10:283-92. 